\title{
"El modelo tiene rostro de sangre". Responsabilidad empresarial en procesos represivos durante la dictadura de Pinochet en Chile (1973-1990)
}

Rodrigo ARAYA GÓMEZ

Universidad Academia de Humanismo Cristiano, Santiago, Chile rodrhistoria@hotmail.com

\section{Magdalena Garcés Fuentes}

Abogada de derechos humanos, Santiago, Chile garcesfmane@gmail.com

\begin{abstract}
Resumen: El artículo tiene por objetivo analizar la responsabilidad de sectores empresariales en la política represiva de la dictadura cívicomilitar chilena. Con ese fin, utiliza bibliografía para comprender el contexto represivo y analiza causas judiciales sobre violaciones a los derechos humanos donde tuvieron participación personas vinculadas al ámbito patronal. De acuerdo con la investigación, sostenemos que civiles tuvieron activa participación en la comisión de delitos. Esto viene a cuestionar la imagen benéfica que los grupos empresariales lograron construir sobre sí mismos con relación a su rol en la dictadura, cuestionamiento que se inserta dentro de los debates sobre la herencia dictatorial.
\end{abstract}

Palabras clave: derechos humanos, empresariado, represión, juicios, dictadura cívico-militar

Recibido: 27 de febrero de 2021 . Aprobado: 16 de abril de 2021. 


\section{Introducción}

El objetivo del artículo es analizar la responsabilidad directa o indirecta de sectores empresariales en la represión ejercida contra dirigentes sindicales, organizaciones o trabajadores y trabajadoras durante la dictadura cívicomilitar. ${ }^{1}$ El tema es de gran relevancia y actualidad por cuanto explora un área prácticamente desconocida para la sociedad chilena, como es el papel de los civiles en la represión dictatorial. En este caso, personajes vinculados al empresariado, un actor que en términos generales logró crear una imagen favorable de sí mismo, ${ }^{2}$ la cual vino a romper las representaciones anteriores que se tenían sobre ellos, vinculadas al conflicto social y político chileno. ${ }^{3}$

Las investigaciones sobre el papel de los civiles en la dictadura se han centrado en su participación como arquitectos de la política económica, ministros y otros altos cargos en la administración pública, asesores de las comisiones legislativas: en otras palabras, como los representantes del personal político del régimen. ${ }^{4}$ En este sentido, estos trabajos tendieron a diseccionar a la dictadura entre el aparato militar, vinculado a las violaciones a los derechos humanos, y el aparato civil, gestor de la obra modernizadora y en última instancia responsable del éxito económico del régimen, traducido en la continuidad del modelo neoliberal por parte de los gobiernos de la CPPD. Por lo tanto, la labor de los civiles en la dictadura, en la gran mayoría de los casos, quedaría vinculada a la "obra positiva” de aquella, omitiendo cualquier posibilidad de juicio ético o moral como partidarios de un régimen que había desarrollado una política activa de violaciones a los derechos humanos.

Esta liberación implícita de responsabilidad afectó o dificultó las posibilidades de desarrollar investigaciones sobre la participación de los civiles en crímenes de la dictadura, salvo casos contados en que algún miembro civil de los aparatos de seguridad estuvo involucrado en la comisión de delitos, situación en que por ejemplo, aparecen como responsables antiguos militantes de izquierda devenidos en delatores e incluso en algunos casos extremos como

$1 \quad$ El artículo cuenta con el respaldo económico del proyecto Fondecyt 11180051.

2 Rolando Álvarez, Gremios empresariales: política y neoliberalismo: los casos de Chile y Perú (1986-2010) (Santiago de Chile: LOM Ediciones, 2015). Véase también Cecilia Montero, La revolución empresarial chilena (Santiago de Chile: CIEPLAN, 1997).

3 Sobre el papel del empresariado en la política durante el siglo XX véase Sofia Correa, Con las riendas en el poder. La derecha chilena en el siglo XX (Santiago de Chile: De Bolsillo Random House Mondadori, 2011).

4. Sobre el rol de los civiles en la dictadura, véase Arturo Fontaine, Los economjstas y el presidente Pinochet (Santiago de Chile: Zig-Zag, 1988). Una perspectiva crítica sobre el papel de los economistas en la dictadura en Juan Gabriel Valdés, Los economistas de Pinochet. La escuela de Chicago en Chile (Santiago de Chile: FCE, 2020). 
torturadores y asesinos; un caso emblemático es el de Miguel Estay Reino, alias "El Fanta".

No obstante, en plena dictadura cívico-militar, periodistas de oposición realizaron reportajes donde dieron a conocer crímenes que involucraron a civiles en labores represivas, aunque sin que se produjese una sistematización sobre los mismos. Los trabajos globales más relevantes correspondieron a la Historia oculta del régimen militar, de Ascanio Cavallo, Óscar Sepúlveda y Manuel Salazar, y Chile: la memoria prohibida, obra donde participaron varios autores. En ambos textos se mencionaron algunos casos emblemáticos de violaciones a los derechos humanos.

Una vez reinstaurada la democracia, desde el ámbito del periodismo de investigación encontramos una serie de artículos y libros que dan cuenta de la participación de empresarios o empresas en labores represivas. En este sentido se destaca el texto de Javier Rebolledo, A la sombra de los cuervos, donde describe la participación de civiles en crímenes que afectaron a un grupo de trabajadores de la Papelera (CMPC) de Laja y en otro caso a campesinos de Paine, donde fue involucrado un familiar de los dueños de cecinas Bavaria. ${ }^{6}$ En otro trabajo, Rebolledo describe los inicios de la Dirección de Inteligencia Nacional (DINA) en Tejas Verdes, destacando el papel de la Pesquera Arauco como colaboradora en el traslado de detenidos o mejor dicho secuestrados. ${ }^{7}$

Otro periodista destacado es Mauricio Weibel, quien ha investigado las acciones de la DINA y el Centro Nacional de Investigaciones (CNI). Con una importante cantidad de documentación, Weibel describe el accionar de los organismos de seguridad, definidos felizmente como "asociación ilícita”, que contó con la participación de funcionarios de la dictadura en el seguimiento y persecución de opositores. ${ }^{8}$

Ahora bien, en el ámbito latinoamericano, nos encontramos con la fuerte influencia de los estudios sobre responsabilidad empresarial en crímenes contra los derechos humanos en Argentina, país donde ha surgido un verdadero campo de estudios sobre la materia que dio lugar a una gran cantidad de trabajos que han logrado describir los procesos represivos al interior de las empresas y el rol de los dueños o ejecutivos de ellas. Aquí cabe

5 Sobre la vida de Miguel Estay Reino, véase Nancy Guzmán, El Fanta: historia de una traición (Santiago de Chile: Ceibo Ediciones, 2016).

6 Javier Rebolledo, A la sombra de los cuervos. Los cómplices civiles de la dictadura (Santiago de Chile: Ceibo Ediciones, 2016).

7 Javier Rebolledo, El despertar de los cuervos: Tejas Verdes, el origen del exterminio en Chile (Santiago de Chile: Ceibo Ediciones, 2013).

8 Mauricio Weibel, Asociación ilícita: los archivos secretos de la dictadura (Santiago de Chile: Ceibo Ediciones, 2012). 
mencionar dos grandes obras: Cuentas pendientes. Los cómplices económicos de la dictadura, de Juan Pablo Bohoslavsky y Horacio Verbitsky, ${ }^{9}$ y Responsabilidad empresarial en delitos de lesa humanidad. Represión a trabajadores durante el terrorismo de Estado, ${ }^{10}$ obra en dos tomos coordinada por Victoria Basualdo entre otros académicos especialistas en el tema y con la colaboración de varias instituciones como la FLACSO, el CELS, el Programa Verdad y Justicia y la Secretaría de Derechos Humanos. Estos textos han servido de elemento probatorio, bajo la figura del contexto, para apoyar una serie de causas penales en contra de empresarios vinculados a violaciones a los derechos humanos. Se trata de juicios que han logrado importantes resultados, como la condena del dueño de La Veloz del Norte, Marcos Levín, y el juicio en contra de los ejecutivos de Ford Argentina, que también se ha resuelto con sentencias a favor de los trabajadores que denunciaron crímenes al interior de la empresa. ${ }^{11}$

En Chile, en tiempo reciente, se publicó la obra colectiva compilada por Juan Pablo Bohoslavsky, Karinna Fernández y Sebastián Smart, el primer gran estudio que aborda en forma global la responsabilidad de los empresarios con la dictadura cívico-militar e incluye un capítulo específico sobre la participación de empresas en crímenes de lesa humanidad que relata los casos de Pesquera Arauco y Colonia Dignidad. ${ }^{12}$ Es relevante porque ubica en la órbita del espacio público la discusión sobre el papel de los empresarios en la política represiva de la dictadura, ya sea como partícipes directos o como agentes facilitadores de los crímenes, abriendo un espacio que tiene todavía un amplio campo desde donde desarrollarse.

La escasez de trabajos sobre el tema se debería a tres grandes factores. En primer lugar, a la dificultad de acceder a las fuentes o a la dispersión de ellas; por ejemplo, la información contenida en el Informe de la Comisión Nacional de Verdad y Reconciliación (conocido como Informe "Rettig”, por el apellido del presidente de la Comisión) y la de la Comisión Nacional sobre Prisión

$9 \quad$ Horacio Verbitsky y Juan Pablo Bohoslavsky, Cuentas pendientes. Los cómplices económicos de la dictadura (Buenos Aires, Siglo XXI Editores, 2014).

10 Victoria Basualdo y otros, Responsabilidad empresarial en delitos de lesa humanidad. Represión a trabajadores durante el terrorismo de Estado (Posadas: Editorial Universitaria Universidad Nacional de Misiones, 2016).

11 En Colombia se ha publicado un libro donde se analiza el rol de una comisión de verdad sobre el papel de las empresas en violaciones a los derechos humanos: Nelson Sánchez León, Leigh Payne, Gabriel Pereira, Laura Bernal, Daniel Martin y Miguel Barboza, Cuentas claras. El papel de la Comisión de la Verdad en la develación de la responsabilidad de empresas en el conflicto armado colombiano (Bogotá: Ediciones Antropos, 2018).

12 Juan Pablo Bohoslavsky, Karinna Fernández y Sebastián Smart, Complicidad económica con la dictadura chilena. Un país desigual a la fuerza (Santiago de Chile: LOM Ediciones, 2018). 
Política y Tortura (“Comisión Valech") no está disponible para el público en general por disposiciones legales que garantizan el secreto de la identidad de los victimarios, lo cual constituye un serio obstáculo para las investigaciones sobre los crímenes de la dictadura. ${ }^{13}$ Estos mismos obstáculos legales se encuentran en el Ministerio de Defensa Nacional puesto que esta entidad está eximida de transferir su documentación al Archivo Nacional. ${ }^{14}$ Es un privilegio que le ha permitido resguardar información sensible, emanada de los servicios de seguridad de la dictadura, o expurgarla en caso de ser necesario. Por lo tanto, no existe un fondo específico que contenga información de los servicios de seguridad de la dictadura, sino solo datos dispersos en diversas instituciones del Estado.

Un segundo factor que ha impedido la expansión de este campo de estudio corresponde a la inconveniencia manifestada por muchos sectores políticos durante los primeros gobiernos democráticos de investigar en profundidad los crímenes de la dictadura. Así, las orientaciones políticas de estos gobiernos habrían estado influenciadas por la necesidad de asegurar la paz social y mantener las reglas del juego en todos los ámbitos, entre ellos el

13 La Ley 19.123, que crea la Corporación Nacional de Reparación y

Reconciliación (CNRR), estableció en su art. 2 N. ${ }^{\circ} 3$ que una de las funciones de la Corporación era "guardar en depósito los antecedentes reunidos tanto por la Comisión Nacional de Verdad y Reconciliación como por la Corporación Nacional de Reparación y Reconciliación y todos aquellos que, sobre casos y asuntos similares a los por ella tratados, se reúnan en el futuro". En el inciso $2^{\circ}$ del art. 2 , señala que "el acceso a la información deberá asegurar la absoluta confidencialidad de ésta, sin perjuicio que los Tribunales de Justicia puedan acceder a dicha información, en los procesos sometidos a su conocimiento”. En términos prácticos, se estableció una reserva parcial de los antecedentes por cuanto éstos sólo podían ser puestos en conocimiento de los Tribunales de Justicia. En cambio, la Ley 19.992, que estableció beneficios para las personas reconocidas como víctimas de prisión política y tortura por la Comisión Valech, estableció en su artículo 15 el secreto absoluto respecto de los documentos, testimonios y antecedentes aportados por las víctimas ante la Comisión Nacional sobre prisión Política y Tortura, por el plazo de 50 años. Tras el término de la CNRR el año 1996, se dictó el Decreto Supremo N. ${ }^{\circ} 1005$ del Ministerio del Interior que traspasó la custodia de los antecedentes reunidos por la Comisión Nacional de Verdad y Reconciliación (CNVR) y la CNRR al Programa de Derechos Humanos del Ministerio del Interior, actualmente Unidad Programa de Derechos Humanos del Ministerio de Justicia y Derechos Humanos. El artículo $1^{\circ}$ del referido decreto estableció que "estos antecedentes tendrán carácter confidencial, sin perjuicio que los Tribunales de Justicia puedan acceder a ellos en los procesos sometidos a su conocimiento”.

Finalmente, la Ley 20.405 que crea el Instituto Nacional de Derechos Humanos (INDH) traspasó la custodia de los antecedentes reunidos por las diferentes comisiones de verdad al Instituto, sin perjuicio de que el Programa de Derechos Humanos podrá mantener los antecedentes que posee en custodia hasta el término de sus funciones (art. $\left.3^{\circ} \mathrm{N} .^{\circ} 6\right)$.

14. Ley 18.771 del 17 de enero de 1989. 
jurídico, de forma tal que cualquier tipo de juicio o causa penal en contra de personeros que hubiesen apoyado la pasada dictadura se consideraba una falta de prudencia y un atentado al orden jurídico. ${ }^{15}$ Además, considerando los altos grados de continuidad del bloque de poder dictatorial, afincados por ejemplo en los principales medios de comunicación, se tornaba complejo abordar temas o noticias que tuvieran que ver con la participación o la responsabilidad de empresas en crímenes de lesa humanidad, no obstante que los rumores fluyeran o existiesen testimonios en redes sociales que atestiguasen acciones en esa órbita.

Finalmente, y con relación al segundo factor, el empresariado en cuanto actor político-social experimentó un profundo cambio en su relación con la sociedad chilena. Si en el periodo previo al golpe fue considerado como un elemento contrario a los intereses nacionales, enemigo del socialismo y aliado del imperialismo, en el periodo dictatorial buscó cambiar esta imagen; en la década de 1980 los empresarios comenzaron a ser considerados como los principales agentes del desarrollo nacional, un papel que le reconocieron la gran mayoría de los sectores políticos y los medios de comunicación, donde tenían tribuna como constructores del espacio público. ${ }^{16}$ En virtud de este nuevo papel, los aspectos más oscuros y vinculados a la represión dictatorial fueron omitidos, o mencionados tangencialmente como una realidad de la cual no fueron partícipes, privilegiándose por tanto su papel en el crecimiento económico del país durante la aplicación del modelo neoliberal. Este silencio también se puede observar en la escasa cantidad de estudios sobre el proceso de privatización de las empresas estatales. ${ }^{17}$

\section{Contexto histórico: represión al movimiento sindical, políticas proempresariales y dispositivos legales facilitadores de la represión antisindical}

Desde sus inicios, la dictadura cívico-militar aplicó una fuerte política represiva en contra de los trabajadores y sus organizaciones. La identificación de la mayoría del movimiento obrero-sindical con la Unidad Popular, basada en profundos lazos históricos construidos durante más de 80 años de lucha, significó que los trabajadores partidarios de la izquierda fuesen perseguidos por las nuevas autoridades militares. La máxima central sindical, la Central

15 Edgardo Boeninger, Democracia en Chile. Lecciones para la gobernabilidad (Santiago de Chile: Editorial Andrés Bello, 1997), 430.

16 Rolando Álvarez, Gremios empresariales: política y neoliberalismo: los casos de Chile y Perú (1986-2010) (Santiago de Chile: LOM Ediciones, 2015).

17 Una clásica obra de denuncia sobre las privatizaciones en la dictadura es el libro de María Olivia Monckeberg, El saqueo de los grupos económicos al Estado chileno (Santiago de Chile: Ediciones B, 2001). 
Única de Trabajadores (CUT), fue declarada ilegal y sus bienes confiscados. Centenares de dirigentes sindicales fueron detenidos, torturados y en varios casos ejecutados sumariamente o desaparecidos. De acuerdo con la información proporcionada sobre las víctimas en el Informe Rettig, la persecución no distinguió entre dirigentes de base, afiliados o dirigentes de federaciones de rama. En este sentido, las represiones masivas tenían por objetivo impedir cualquier resistencia por parte de los sindicatos, que vivieron un periodo de terror que dificultó su vida interna y capacidad de representación de sus afiliados.

Junto a la represión física, la dictadura dictó una serie de normas de emergencia en formato de decreto-ley o bando. El más relevante en esta primera etapa fue el DL 198, que prorrogó los mandatos de las directivas sindicales elegidas antes del golpe de Estado del 11 de septiembre de 1973, pero junto a ello, en el caso de ausencia de dirigentes, estableció un mecanismo de designación en base a una lista de trabajadores con una cantidad mínima de años de duración en la empresa y sin filiación política reconocida.

Con las directivas sindicales intervenidas se facilitó el despido de trabajadores: hacia fines de 1973 se despidió a más de 100.000 personas en la administración pública. Las causales de despido aumentaron: se incorporó, por ejemplo, la realización de acciones vinculadas a la paralización de faenas, destrucción de maquinaria, entre otras. El Código del Trabajo del año 1931 fue suspendido en la práctica: los principales derechos de los trabajadores, como el derecho a huelga y la negociación colectiva, no fueron aplicables; y en el caso de los derechos individuales la estabilidad en el empleo fue cuestionada en base a nuevos principios como la flexibilidad laboral. De este modo, los trabajadores en su conjunto quedaron desprotegidos frente a los empleadores, reafirmándose los rasgos más nocivos de una relación laboral asimétrica a nivel de empresa.

El estado de desprotección de los trabajadores se consolidó en 1979 con la imposición del llamado Plan Laboral, un conjunto de decretos-leyes que tuvieron por objetivo adecuar la legislación laboral al modelo neoliberal. Las nuevas normas establecieron la libertad de afiliación sindical, mediante la cual se permitió la constitución de varios sindicatos en una misma empresa; al mismo tiempo, la afiliación y el pago de cuotas pasó a tener carácter voluntario. Se restringió el derecho a huelga, estableciendo un plazo de duración máximo de 60 días y dando derecho al empleador a contratar reemplazantes durante dicho periodo. La negociación colectiva por rama se aceptaba sólo a nivel de empresa y quedaron excluidos de dichas negociaciones diversos grupos de trabajadores como los agrícolas, marítimos y de la construcción. En este mismo sentido, los sindicatos se dividieron en cuatro categorías: de empresa, inter-empresa, transitorios y eventuales; sólo 
tenían derecho a negociar colectivamente los pertenecientes al primer grupo. ${ }^{18}$ Estas normas tuvieron por resultado la drástica disminución de la afiliación sindical, que en 1983 llegaba sólo a poco más de un 10 \%. Esta pérdida fue aún más fuerte en el sector agrario donde la población sindicalizada —que había alcanzado su nivel más alto en 1973 con 313.770 afiliados—-se redujo a 46.466 personas en $1990 .^{19}$

A pesar de las promesas iniciales de la Junta Militar respecto a respetar las conquistas de los trabajadores, en la práctica no se cumplieron las expectativas de una continuidad de los avances obtenidos por el movimiento sindical, predominando claramente un enfoque proempresarial de la política económico-social. De este modo, se devolvió un importante porcentaje de las empresas intervenidas durante la Unidad Popular a sus antiguos dueños; mientras que, en otros casos, las empresas estatizadas fueron privatizadas en un proceso que se extendió en una primera etapa entre los años 1974 y 1975. En el mundo del agro, las nuevas autoridades devolvieron muchos de los predios expropiados a sus antiguos dueños, mientras que los campesinos que habían tenido participación en tomas de fundos fueron excluidos de la asignación de parcelas por parte de la Corporación de la Reforma Agraria (CORA), situaciones englobadas en un proceso conocido como contrarreforma agraria. ${ }^{20}$

Además, la política económica del nuevo gobierno tuvo una orientación marcadamente liberal pero con un diseño gradual respecto a la apertura comercial y control de precios, con el objetivo de evitar los costes sociales de un ajuste económico. ${ }^{21}$ De acuerdo a esos objetivos, el nuevo gobierno contó con el apoyo unánime del empresariado, que había luchado fuertemente en contra del gobierno de la Unidad Popular. ${ }^{22}$ Los gremios empresariales apoyaron el llamado “proceso de reconstrucción del país”, tarea que según ellos adquiría un carácter nacional: había que construir un nuevo Chile después del caos que había generado el proyecto socialista del gobierno de Salvador Allende. A partir de esta adhesión, las organizaciones de

18 Para una visión general sobre el impacto del modelo neoliberal en las relaciones laborales ver Guillermo Campero y José Antonio Valenzuela, El movimiento sindical en el régimen militar chileno: 1973-1981 (Santiago de Chile: ILET, 1984).

19 Sergio Gómez, "Organización Campesina en Chile: Reflexiones sobre su debilidad actual”, Revista Austral de Ciencias Sociales, 6 (2002): 3-18.

20 Hugo Villela, Saqueo y exterminio de la clase campesina chilena. La Contra Reforma Agraria del régimen civil y militar, 1973-1976 (Santiago de Chile: LOM Ediciones, 2016).

21 Manuel Gárate, La revolución capitalista de Chile (1973-2003) (Santiago de Chile, Ediciones Universidad Alberto Hurtado, 2012).

22 Guillermo Campero, Los gremios empresariales en el periodo 1970-1983: comportamiento sociopolítico y orientaciones ideológicas (Santiago de Chile: ILET, 1984). 
empresarios colaboraron con el gobierno, tanto a nivel de participación de exdirigentes en labores administrativas como en la formación de una base social de apoyo, descartándose cualquier crítica a las políticas de violaciones a los derechos humanos.

Este apoyo incondicional a la dictadura continuó incluso en el momento en que la política económica fue asumida en su totalidad por el equipo económico de los "Chicago Boys". ${ }^{23}$ Las políticas implementadas por este grupo de economistas neoliberales a partir del año 1975, hito que se conoció como el ladrillazo, tuvieron graves consecuencias en el aparato productivo y la clase trabajadora chilena. Las políticas neoliberales se aplicaron sin ningún tipo de gradualidad, lo que implicó un escenario desregulado de competencia de la industria nacional con la libre importación de productos del extranjero, junto al ingreso masivo de capitales extranjeros que acentuaron la dependencia de la economía chilena respecto al mercado mundial.

El ladrillazo provocó altas tasas de cesantía, aumento de la pobreza y desigualdad en la distribución del ingreso, y la desprotección de las familias de los sectores populares por la disminución del gasto social. La contracción del consumo afectó a la industria nacional menoscabando la producción y los salarios: las empresas debieron realizar grandes esfuerzos para sobrevivir en un nuevo escenario político-económico que impedía cualquier tipo de disidencia a los dictámenes estatales.

En ese escenario, adquirió relevancia la política represiva llevada a cabo por la dictadura cívico-militar -con la complicidad de los empresarios- puesto que la magnitud de los costos sociales por la aplicación del modelo neoliberal podría implicar una fuerte resistencia. La acción coercitiva de los aparatos de seguridad y sus apoyos civiles fue funcional a la imposición del neoliberalismo; los actos de violencia, como la legislación restrictiva de los derechos laborales, tuvieron por objetivo atemorizar a los trabajadores e impedir cualquier acción reivindicativa que pusiera en cuestión el modelo y la obtención de beneficios por parte de los patrones en la gestión de las empresas.

La finalidad represiva de la política laboral de la dictadura tuvo también un trasfondo de revanchismo patronal, debido al rechazo y trauma que generó la experiencia de la Unidad Popular en el empresariado. Este propósito se puede advertir, en el caso de la represión en el campo, especialmente en las zonas donde los procesos de reforma agraria generaron grandes fricciones entre los propietarios expropiados y los campesinos movilizados, como en los casos de Yumbel y Paine, donde propietarios y civiles ligados a éstos

23 Manuel Gárate, La revolución capitalista de Chile; Pilar Vergara, Auge y caída del neoliberalismo en Chile (Santiago de Chile: FLACSO, 1985). 
realizaron detenciones en colaboración con carabineros de la zona. ${ }^{24}$ Respecto a la situación en las industrias, se conoce el caso (denunciado por testigos) de la empresa Elecmetal, que había participado en el Cordón Industrial Vicuña Mackenna y donde el día 17 de septiembre de 1973 se realizaron detenciones de dirigentes sindicales; entre ellos, los hermanos Juan y Miguel Fernández Cuevas, quienes junto a otros cuatro trabajadores fueron encontrados muertos en la calle al día siguiente de su detención. En esta acción habrían colaborado directivos de la empresa, entregando a dichos dirigentes a efectivos policiales al interior de la planta. ${ }^{25}$ Junto a estas situaciones expresivas de una violencia irracional, se pueden encontrar casos que se vinculan a políticas represivas de empresas o de directa participación de empresarios o dueños de fundos.

Los casos reseñados en el presente artículo fueron elegidos por cuanto se realizó una investigación judicial de los mismos, estableciéndose la responsabilidad directa de actores económicos, empresarios o propietarios de grandes extensiones de tierras.

Como ya se mencionó, la investigación judicial sobre crímenes de lesa humanidad durante la dictadura se ha centrado en la participación de agentes del Estado, principalmente carabineros o militares, y someramente en la participación de civiles; por ello, judicialmente se ha establecido la responsabilidad e identidad de los civiles de manera muy parcial y se hace difícil aventurar una categorización o estandarización de las pertenencias o móviles de estos últimos. A pesar de estas indagaciones limitadas, en algunos casos se logró acreditar la responsabilidad de civiles. La información no sistematizada de las investigaciones judiciales permite identificar una relación de los partícipes civiles con intereses económicos afectados por la reforma agraria, la toma de fundos o empresas o, en términos generales, la política económica del gobierno democrático destituido.

\section{La participación de civiles en la represión}

Como ya se ha venido sosteniendo en las páginas anteriores, después del golpe de Estado de 1973 las Fuerzas Armadas y de Orden, con la activa colaboración de la policía de investigaciones (policía civil) y de civiles, desarrollaron una masiva y sistemática violación de derechos humanos en el país, dirigida en contra de los integrantes y adherentes del gobierno depuesto

24. José Bengoa, Reforma agraria y revuelta campesina: seguido de un homenaje a los campesinos desaparecidos (Santiago de Chile: LOM Ediciones, 2016).

25 Informe de la Comisión Nacional de Verdad y Reconciliación (CNVR), reedición de CNRR, (Santiago de Chile: Andros Impresores, 1996), 143-144. 
y de otros partidos de izquierda, como el Movimiento de Izquierda Revolucionaria, MIR. En los primeros meses de la dictadura,

se practicaron allanamientos masivos, detenciones, torturas y ejecuciones de dirigentes sociales, sindicalistas, pobladores, campesinos y estudiantiles; es decir, la represión se aplicó al conjunto del "movimiento popular" chileno. También fueron perseguidos funcionarios de la Fuerzas Armadas que habían formado parte del gobierno de la Unidad Popular o habían manifestado su simpatía por éste. Además, fueron detenidas, asesinadas o desaparecidas personas sindicadas como "revoltosas" o "conflictivas" por las nuevas autoridades: minorías sexuales, personas alcohólicas, hombres que golpeaban a sus esposas, delincuentes comunes, etc. En este sentido, parte de los objetivos de la violación de derechos humanos en esta primera etapa fue castigar y disciplinar al pueblo en su conjunto. ${ }^{26}$

El Informe de la Comisión Nacional de Verdad y Reconciliación señala, respecto a las detenciones realizadas entre septiembre y diciembre de 1973, que estas fueron efectuadas "por patrullas de carabineros, a veces ayudados por efectivos de Investigaciones y civiles”. ${ }^{27}$ Respecto del fenómeno de la desaparición forzada de personas en estos primeros meses de dictadura, el Informe sostiene que "las detenciones al parecer fueron practicadas, en distintos puntos del país, por diversas unidades de uniformados, a veces acompañados de civiles". ${ }^{8}$ En la Región del Bío Bío, el citado informe identifica que, "en algunas comunas o localidades, como Santa Bárbara, Quilaco, Quilleco, Mulchén, hubo una activa participación de civiles organizados en los hechos de violación de los derechos humanos". ${ }^{29}$

Respecto del tipo de participación de los civiles, el Informe señala que algunos denunciaron, otros actuaron en forma autónoma con conocimiento de la autoridad y algunos directamente participaron en interrogatorios y torturas en recintos militares.

Estos casos de participación de "civiles" se registran también en una zona campesina de la Región Metropolitana (Paine), en la Región del Maule, la Región de la Araucanía y la Región de Los Lagos; ${ }^{30}$ territorios en los cuales se había implementado la reforma agraria o donde existían fundos previamente tomados por campesinos y/o trabajadores y que posteriormente habían pasado a manos del Estado a través de la Corporación de la Reforma

26 Magdalena Garcés Fuentes, “Terrorismo de Estado en Chile: la campaña de exterminio de la DINA en contra del MIR” (Tesis doctoral, Universidad de Salamanca, enero de 2016), 14.

27 Informe Rettig, 109.

28 Informe CNVR, 22.

29 Informe CNVR, 325.

30 Informe CNVR, 125 y 225 y ss., 308, 369 y 394. 
Agraria, CORA o de la Corporación de Fomento de la Producción, CORFO. ${ }^{31}$ A continuación, revisamos los principales casos con consecuencias judiciales en los que se ha comprobado la participación de civiles -vinculados al ámbito empresarial- en violaciones a los DD.HH.

\section{Caso Etienne Pesle de Menil}

La región de la Araucanía, en el sur de Chile, es un territorio con fuerte presencia de población de origen mapuche ubicada especialmente en sectores rurales. Durante el gobierno de la Unidad Popular, se suscitaron allí grandes conflictos por la aplicación de la ley de Reforma Agraria. Los mapuche lograron recuperar una importante cantidad de tierras usurpadas por colonos chilenos o de origen extranjero: sin embargo, estas acciones a la vez provocaron una fuerte resistencia de los propietarios expropiados, desarrollándose acciones de tomas y retomas de fundos. ${ }^{32}$

En este escenario conflictivo se ejecutó el golpe de Estado y la consiguiente represión en contra de los campesinos y el personal que había colaborado en la aplicación de la reforma agraria. Así, cobraron importancia algunos dueños de fundos y/o agricultores que eran pilotos del Club Aéreo de Temuco y, tras cierto número de horas de vuelo, pasaban automáticamente a la reserva de la Fuerza Aérea de Chile. Estos pilotos-agricultores fueron llamados a prestar servicios tras el golpe de Estado, como interventores de empresas expropiadas, de organismos públicos ligados a la producción y el comercio, etc. Sin embargo, también se ha acreditado, en algunos casos, su intervención activa en labores represivas en asentamientos campesinos o en allanamientos y detenciones en la ciudad de Temuco. Etienne Pesle de Menil, ex sacerdote de origen francés y funcionario del Instituto Nacional de Desarrollo Agropecuario (INDAP), había realizado labores profesionales en fundos tomados por campesinos. Fue detenido en las oficinas de la institución el 19 de septiembre de 1973. Testigos de la detención declararon que participaron en el operativo tres personas vestidas con uniformes de la Fuerza Aérea de Chile, entre los que se encontraba Miguel Manríquez Saber, oficial de reserva que al parecer estaba a cargo del operativo". ${ }^{33}$

Uno de los testigos en el juicio declaró que conoció a Etienne Pesle de Menil en INDAP, agregando que este se encontraba a cargo del departamento de

31 Para una visión general del proceso de reforma agraria, ver José Bengoa, Historia rural de Chile central. Tomo II. Crisis y ruptura del poder hacendal (Santiago de Chile: LOM Ediciones, 2015), 281-348.

32 Véase Martín Correa, Raúl Molina y Nancy Yáñez, La Reforma Agraria y las tierras mapuches. Chile 1962-1975 (Santiago de Chile: LOM Ediciones, 2005).

33 Ministro Mario Carroza Espinosa. Sentencia Rol N. ${ }^{\circ} 2182-98$ Etienne Pesle, 9 de mayo de 2016. Considerando tercero. 
cooperativas en el sector de Lautaro y Galvarino; relató que Etienne Pesle trabajaba en el Fundo San Miguel de Galvarino, que había sido tomado por campesinos y era propiedad de Miguel Manríquez. El día 12 de septiembre, Etienne Pesle fue detenido en las oficinas de INDAP por tres uniformados entre los que se encontraba Manríquez Saber. Señaló en su declaración que Etienne Pesle volvió a INDAP el día siguiente con el pelo rapado y que señaló que sólo había sido interrogado; pero que ese mismo día fue nuevamente detenido. Se encuentra desaparecido hasta la fecha.

De acuerdo con testigos, en la detención de Pesle también habría tenido participación Emilio Sandoval Poo, oficial de reserva de la Fuerza Aérea. ${ }^{34}$ Otros antecedentes en el proceso lograron establecer la participación de Emilio Sandoval Poo en un grupo de funcionarios de la Fuerza Aérea dedicado a labores represivas en la Base Aérea de la ciudad.

La sentencia de primera instancia dio por establecido que el 11 de septiembre de 1973 el Comandante del Grupo N. ${ }^{\circ} 3$ de Aviación de la Base Aérea de Maquehue delegó el mando en el Segundo Comandante Benjamín Fernández. Este organizó un grupo elegido de funcionarios de planta y oficiales de reserva de la Fuerza Aérea para realizar labores de inteligencia con propósitos ilícitos como el allanamiento de viviendas y oficinas de forma indiscriminada. Además, este grupo procedió a la "detención de personas contrarias al régimen militar o partidarias de la administración saliente, sin orden judicial alguna, [para] luego interrogarlos bajo tortura y en ocasiones, llegar a su total eliminación, ocultándose sus restos". ${ }^{55}$ Respecto de la detención de Pesle y su posterior desaparición, la sentencia concluye:

Que esta organización represiva de agentes del Estado, pertenecientes a la Fuerza Aérea de Chile, creada con objetivos criminales, son los que detienen a Etienne Marie Louis Pesle de Menil el día 19 de septiembre, le trasladan hasta su base de operaciones, la Base Aérea de Maquehue, donde al igual que todos los detenidos, lo mantienen amarrado de las manos y con su vista vendada, y le interrogan en el Pabellón de la Comandancia bajo tortura, manteniéndole encerrado sin derecho por tiempo indeterminado en la misma Base Aérea, lugar desde donde no se tiene más conocimiento de su existencia, y desaparece sin que hasta el momento se tenga noticias de su destino ni tampoco registros en que conste su deceso. ${ }^{36}$

Los hechos descritos son tipificados como secuestro calificado y asociación ilícita. Fueron condenados un conjunto de funcionarios de la Fuerza Aérea

34 Sandoval Poo actualmente es empresario y en la época de los hechos se desempeñaba como empresario en el rubro de abarrotes.

35 Ministro Mario Carroza Espinosa. Sentencia Rol N. ${ }^{\circ} 2182-98$ Etienne Pesle, Considerando segundo N. ${ }^{\circ} 2$.

36 Ministro Mario Carroza Espinosa. Sentencia Rol N. ${ }^{\circ} 2182-98$ Etienne Pesle, Considerando segundo N. ${ }^{\circ} 5$. 
junto a Emilio Sandoval Poo, oficial de reserva, de quien se acreditó su participación en el grupo represivo así como su presencia en interrogatorios y torturas a detenidos en la Base Aérea. La sentencia fue confirmada por la Corte de Apelaciones de Santiago ${ }^{37}$ y la Corte Suprema rechazó los recursos interpuestos por la defensa de Emilio Sandoval Poo en contra de la sentencia de la Corte de Apelaciones, ${ }^{38}$ quedando firme la condena.

\section{Complejo Forestal y Maderero Panguipulli, Liquiñe, Chihuio y Neltume}

En el sur de Chile, en la zona cordillerana de la actual Región de los Ríos, un territorio con una importante reserva de bosque nativo, se conformaron una serie de grandes propiedades de explotación forestal. Los trabajadores realizaban sus labores en condiciones precarias mientras que convivían con comunidades de origen mapuche víctimas de la usurpación de sus tierras. Al iniciarse el proceso de reforma agraria durante el gobierno de Eduardo Frei Montalva (1964-1970), los operarios de los fundos forestales de la precordillera valdiviana se organizaron en sindicatos, mientras que militantes del MIR de la zona sur del país, encabezados por el estudiante de agronomía de la Universidad Austral de Valdivia José Gregorio Liendo, apoyaron la movilización de los campesinos y trabajadores forestales reclamando la propiedad de los fundos. El proceso de radicalización del campesinado, incluyendo a las comunidades mapuche de la zona, se vio favorecido por la emergencia del Movimiento Campesino Revolucionario (MCR), uno de los frentes de masas del MIR. ${ }^{39}$ Esta organización apoyó la intensificación del proceso de reforma agraria, incluyendo en ello los predios forestales no contemplados originalmente en la ley.

Las elecciones presidenciales de 1970 y el triunfo de la Unidad Popular encabezada por Salvador Allende sirvieron de estímulo a las demandas de intensificación de la reforma agraria: en ese período se realizaron varias tomas de fundos, entre ellos algunos ubicados en la precordillera de Valdivia. Como afirma Cristóbal Bize, a partir de la toma del fundo Carranco el 26 de noviembre de 1970, los trabajadores organizados comenzaron a tomar los otros fundos madereros de la zona. El 15 de marzo de 1971, el Estado expropió 360.000 hectáreas, ${ }^{40}$ y poco después se constituyó el Complejo

37 Corte de Apelaciones de Santiago, Sentencia Rol N. ${ }^{\circ}$ 1040-2016, 26 de enero de 2018.

38 Corte Suprema, Sentencia Rol N. ${ }^{\circ}$ 3.525-2018, 12 de noviembre de 2019.

39 Jaime Navarrete, Movimiento Campesino Revolucionario, (Santiago de Chile: Ediciones Escaparate, 2018).

40 Cristóbal Bize, El otoño de los raulíes. Poder popular en el Complejo Forestaly Maderero Panguipulli (Neltume, 1967-1973) (Santiago de Chile: Tiempo Robado editoras, 2017), 135. 
Forestal y Maderero Panguipulli (COFOMAP), que pasó a formar parte de la naciente "Área de Propiedad Social". El COFOMAP surgió en una coyuntura propicia para la acción de los movimientos sociales, fruto de décadas de crecimiento del movimiento popular, y se articuló con el gobierno de la Unidad Popular, que ganó las elecciones con un programa de cambios estructurales. Así, siguiendo los planteamientos de Bize, esta experiencia germinó como una empresa estatal,

constituida de hecho durante el verano de 1971, después de que un intenso movimiento social transformara por la vía de la toma de fundos cordilleranos, las relaciones de propiedad, la tenencia de la tierra y el control de los medios de producción a lo largo y ancho del territorio. ${ }^{41}$

El COFOMAP se convirtió en una destacada experiencia de participación democrática de los trabajadores en la gestión de la empresa, enmarcada en la convicción de la construcción del socialismo, razón por la cual el proyecto se vinculó estrechamente al programa de la Unidad Popular. ${ }^{42}$ Sin embargo, esta misma vinculación con la izquierda se tradujo en una fuerte hostilidad de la oposición y la prensa ligada a los grandes propietarios. El Complejo fue denunciado como un "foco guerrillero", supuestamente liderado por José Gregorio Liendo Vera, conocido como el "Comandante Pepe", ${ }_{4}$ constituyéndose en una amenaza potencial para los intereses de los propietarios agrícolas ya que había puesto en entredicho la validez del derecho de propiedad en el espacio público y era un ejemplo para otros sectores sociales movilizados.

La experiencia del COFOMAP tuvo un fin abrupto con el derrocamiento del gobierno de la Unidad Popular. El 12 de septiembre de 1973, habitantes de Complejo (algunos de ellos militantes del MIR o integrantes del Movimiento de Campesinos Revolucionarios, MCR) realizaron un intento de asaltar el retén de carabineros de Neltume, que duró unas 3 horas. ${ }^{44}$ Tras un diálogo con los carabineros, éstos dispararon contra los pobladores y trabajadores forestales. A raíz de este hecho y la representación del Complejo como "foco guerrillero", se desató una cruenta represión en la zona. ${ }^{45} \mathrm{Al}$ territorio de

4.1 Bize, El otoño de los raulíes, 23-24.

42 Sobre la experiencia del COFOMAP véase las memorias del ex dirigente del complejo José Manuel Bravo Aguilera, De Carranco a Carrán. Las tomas que cambiaron la historia (Santiago de Chile: LOM Ediciones, 2012).

43 Liendo Vera fue un conocido dirigente del MIR que realizó trabajo político en la zona cordillerana de Valdivia.

44 Informe CNVR; José Manuel Bravo Aguilera, De Carranco a Carrán.

45 Liendo Vera y otras 11 personas, trabajadores del COFOMAP y dirigentes de MIR, fueron detenidos y juzgados en Valdivia por un Consejo de Guerra, acusados de haber participado en el asaltado el retén de carabineros de Neltume. Fueron fusilados entre los días 3 y 4 de octubre de 1973. Informe CNVR, 397 y 
Neltume fueron enviados destacamentos de regimientos de las ciudades de Temuco, Valdivia y Lautaro, además de efectivos de la Base Aérea Maquehue de la Fuerza Aérea y tropas de la Escuela de Comando y Paracaidismo del Ejército de Peldehue. ${ }^{46}$ En al menos uno de los procesos judiciales sustanciados por el secuestro y/u homicidios de habitantes de la zona se logró establecer la participación directa de un empresario del territorio cordillerano. ${ }^{47}$

En octubre de 1973, fueron detenidos quince trabajadores madereros del Complejo en la localidad de Liquiñe. ${ }^{48}$ En la causa por la desaparición de once de los afectados fueron condenados un Capitán de Ejército y el civil Luis Osvaldo García Guzmán, hijo del propietario de las “Termas de Liquiñe”, empresa turística de la zona donde se asentaron las tropas militares. García padre ya había fallecido cuando se inició la investigación, que logró demostrar que militares guiados por Luis García Guzmán procedieron a secuestrar y conducir a los trabajadores forestales hasta el Puente Toltén, camino a Villarrica, donde fueron fusilados y sus cuerpos lanzados al río. ${ }^{49}$ García indicó los domicilios de las víctimas y acompañó la comitiva militar. ${ }^{50}$

En el proceso Chihuio, por el secuestro calificado de 17 personas, fue condenado el militar a cargo del operativo que detuvo a las víctimas, las cuales fueron trasladadas a la casa patronal del Fundo Chihuio, de propiedad de particulares, para posteriormente ser asesinadas e inhumadas clandestinamente a unos quinientos metros de allí..$^{51}$

398. Ministra Patricia González Quiroz, Sentencia Rol N. ${ }^{2}$ 182-98 Caravana episodio Valdivia, 22 de noviembre de 2017.

46 Ver Causa Rol N. ${ }^{\circ}$ 2182-98 Jaime Eltit, sustanciada por el Ministro en Visita Alejandro Madrid, Causa Rol N. ${ }^{\circ} 38.483$ del $19^{\circ}$ Juzgado del Crimen de Santiago; Causa Rol N. ${ }^{\circ}$ 2182-98 Liquiñe, sustanciada por el Ministro Alejandro Solís Muñoz; Causa Rol N. ${ }^{\circ}$ 2182-98 Caravana Valdivia, sustanciada por la Ministra Patricia González.

47 Ministro Alejandro Solís Muñoz, Sentencia Rol N. ${ }^{\circ}$ 2182-98 Episodio Liquiñe, 28 de enero de 2006.

48 Informe CNVR, 401.

49 Ministro Alejandro Solís Muñoz, Sentencia Rol N. ${ }^{\circ}$ 2182-98 Episodio Liquiñe, de 28 de enero de 2006. En primera instancia, Hugo Guerra fue condenado a 18 años de presidio y Luis García Guzmán a 5 años y un día. Condenas confirmadas por la Corte de Apelaciones de Santiago (Rol N. ${ }^{\circ} 2.136,1$ de agosto de 2007). La Corte Suprema rebajó la pena de Hugo Guerra Jorquera a 5 años y la de Luis García a 3 años y un día, otorgándoles a ambos el beneficio de la libertad vigilada, por lo cual pudieron cumplir su condena en libertad (Rol N. ${ }^{\circ}$ 4.662-07, 25 de septiembre de 2008).

50 Ídem.

51 Ministro Alejandro Solís Muñoz, Sentencia Rol N. ${ }^{\circ}$ 2182-98 Episodio Chihuio, de 24 de junio de 2005, Corte de Apelaciones de Santiago, Sentencia Rol N. ${ }^{\circ}$ 22924-2005, 22 de junio de 2006; ministro Jorge Zepeda Arancibia, Sentencia 
Muchos trabajadores fueron detenidos y familias completas de los trabajadores sindicalizados, vinculados a la izquierda o sospechosos de tener simpatía con la misma, fueron expulsadas de los pueblos y asentamientos ubicados al interior del Complejo. Allí los sindicatos estaban prohibidos al igual que en todo el país. Los militares habían dejado el territorio liberado de cualquier posible organización y/u oposición de los trabajadores a la nueva administración designada por la intervenida CORFO, que en unos cuantos años devolvió a manos privadas las montañas y bosques de la zona. El proceso terminó a fines de la década de 1980 con la venta de los últimos fundos que habían pertenecido al COFOMAP. ${ }^{52}$

\section{El caso "Paine"}

La localidad agrícola de Paine, ubicada en la región metropolitana, sufrió entre septiembre y noviembre de 1973 la desaparición o ejecución de 70 personas, la mayoría campesinos que habían participado del proceso de reforma agraria y sindicalización campesina. ${ }^{53}$ La alta cantidad de muertos provenientes de esta localidad la convirtió en el lugar con la mayor proporción de víctimas de violaciones a los DD.HH. ${ }^{54}$ Ello se debía al conflictivo pasado reciente de la zona por la aplicación de la reforma agraria que motivó reacciones de venganza o revanchismo por parte de los propietarios expropiados y sus seguidores.

De acuerdo con el Informe de la CNVR, los operativos fueron realizados por personal de carabineros y del Ejército, "acompañados de civiles de la localidad que colaboraron en una represión que estuvo principalmente dirigida en contra de campesinos del sector". ${ }^{55}$

La investigación judicial de los diversos operativos en la localidad fue dividida por "episodios". En la causa Rol N. ${ }^{\circ}$ 4-2002 Bis, Paine, Episodio "Collipeumo", sustanciada por la ministra Marianela Cifuentes, se investigó la participación directa del empresario transportista Juan Francisco Luzoro Montenegro. En la sentencia de primera instancia se logró establecer que, junto a la participación de carabineros pertenecientes a los retenes de

Rol N. ${ }^{\circ}$ 2182-98 Episodio Chihuio, 30 de noviembre de 2007; Corte de Apelaciones de Santiago Sentencia Rol N. ${ }^{\circ} 2715-2008,1$ de julio de 2009; Corte Suprema, Sentencia Rol N. ${ }^{\circ}$ 2715-2008, 27 de enero de 2011.

52 Sobre el proceso de privatización del Complejo Maderero y Forestal Panguipulli véase Karen Alfaro, “Acumulación por desposesión en Chile: el caso del Complejo Forestal y Maderero Panguipulli en el sur de Chile (1973-1990)", Historia 396, 2 (2016): 225-259.

53 Datos del Informe CNVR, 225 y ss.

54 Ruby Weitzzel, El callejón de las viudas (Santiago de Chile: Planeta, 2001).

55 Informe CNVR, 225. 
Hospital, Champa, Chada, Pintué y Huelquén, se vieron involucrados "varios civiles, dueños de tierras y/o vehículos menores y de carga [que] comenzaron a colaborar activamente con el transporte de personal y de detenidos, entre ellos Juan Francisco Luzoro Montenegro, presidente del Sindicato de dueños de camiones de Paine". ${ }^{56}$

La sentencia señala que, el 17 de septiembre de 1973, Carlos Chávez Reyes, Raúl del Carmen Lazo Quinteros, Orlando Enrique Pereira Cancino y Pedro Luis Ramírez Torres, del asentamiento "Paula Jaraquemada, a instancias del presidente del asentamiento, se presentaron en la Subcomisaría de Carabineros de la misma comuna, quedando detenidos en dicho recinto. El mismo día se presentó en la unidad Alejandro del Carmen Bustos González, que también fue detenido. En las horas siguientes, funcionarios policiales interrogaron y golpearon a los detenidos. En la madrugada del día siguiente, los cinco detenidos fueron sacados de la Subcomisaría y trasladados al sector de Collipeumo".

La sentencia agrega: "la comitiva que trasladó a los detenidos estaba conformada por varios vehículos, ocupados por personal de carabineros y por civiles, entre ellos Juan Francisco Luzoro Montenegro, todos al mando del sargento Manuel Antonio Reyes Álvarez, ex jefe del Retén Hospital”. En el sector Collipeumo, los detenidos fueron fusilados por orden de Reyes Álvarez. En la ejecución participaron carabineros y civiles. Posteriormente, los cuerpos de las víctimas fueron arrojados a un canal, "entre otros por Luzoro Montenegro, en la creencia de que todos ellos habían fallecido". ${ }^{57}$

Los hechos fueron tipificados como homicidios calificados en grado de consumado de las cuatro víctimas, y de homicidio calificado frustrado respecto de la víctima sobreviviente. Luzoro Montenegro fue condenado en calidad de autor de los delitos. En su declaración señaló que para el 11 de septiembre de 1973 era presidente del sindicato de camioneros de Paine y que el día previo al golpe personal militar le había solicitado camiones con barandas para transportar personal. El 11 de septiembre estaba en su domicilio con camioneros, agricultores y comerciantes y el Capitán encargado de la Subcomisaría de Paine lo visitó para solicitarle vehículos, también para transporte de personal. Aunque negó ante el Tribunal su participación en los hechos, señaló que puso a disposición de la policía una camioneta y un automóvil, y que "tanto él como el resto de los civiles que cooperaron con carabineros se limitaron a escoltarlos. Que, en un par de

56 Ministra Marianela Cifuentes Alarcón, Sentencia Rol N. ${ }^{\circ}$ 4-2002 Bis, Paine, Episodio "Collipeumo", de 31 de marzo de 2016. Considerando décimo cuarto.

57 Ídem. 
ocasiones, acompañó a carabineros a detener gente, siempre de noche, pero no ingresó a los domicilios, sólo observó desde lejos". ${ }^{58}$

Sin embargo, Alejandro del Carmen Bustos González, sobreviviente de los hechos, reconoció la presencia de Luzoro al interior de la unidad policial y lo identificó como una de las personas que disparó en su contra. Otro testigo identificó a Luzoro en la Subcomisaría el día de los hechos con una pistola al cinto y reconoció el automóvil de Luzoro integrando la comitiva de diez o doce vehículos que llevaron a los detenidos a Collipeumo.

Juan Francisco Luzoro fue condenado a veinte años de presidio y penas accesorias. Esta sentencia, del 31 de marzo de 2016, fue confirmada por la Corte de Apelaciones de San Miguel.59 La Corte Suprema rechazó los recursos presentados por las defensas de los condenados, pero acogió el recurso presentado por el representante de los familiares de una de las víctimas fallecidas y del sobreviviente de los hechos, por cuanto la sentencia de primera instancia había rechazado algunas de las demandas de indemnización por perjuicios. En sentencia de reemplazo, la Corte Suprema confirmó la sentencia de la ministra Cifuentes (primera instancia) en la parte penal, manteniendo la condena a Luzoro y acogió las demandas originalmente rechazadas, reparando a las víctimas y sus familiares. ${ }^{60}$

\section{Caso CMPC Laja}

Uno de los casos más emblemáticos de participación de civiles en la represión lo constituye el asesinato de un grupo de trabajadores de la empresa Compañía Manufacturera de Papeles y Cartones, filial Laja (CMPC), conocida popularmente como la "Papelera". Esta compañía de larga tradición en el país, fundada en 1920, pertenecía a la familia Matte y contaba con el exmandatario Jorge Alessandri Rodríguez como presidente de su directorio. La CMPC tenía el monopolio de la producción del papel y en un proceso de diversificación de actividades se amplió a la producción de celulosa y conformó Forestal Mininco. Debido a su poder económico y político, el gobierno de la Unidad Popular intentó incorporar la empresa al Área de propiedad social, algo que fue rechazado por la compañía y por un sector de los trabajadores sustentados por la oposición y medios de prensa encabezados por El Mercurio, que impulsaron la campaña "La Papelera No". Sin embargo, dirigentes sindicales de la propia compañía apoyaron la exigencia de

\footnotetext{
58 Sentencia Rol N. ${ }^{\circ}$ 4-2002 BIS, Considerando décimo sexto.

59 Corte de Apelaciones de San Miguel, Sentencia Rol N. ${ }^{\circ}$ 58-2016 - CRIM, 20 de diciembre de 2016.

60 C.S. Sentencia Rol N. ${ }^{\circ}$ 1.568-2017, 16 de noviembre de 2017.
} 
estatización, destacando entre ellos los pertenecientes a la filial Laja de la empresa.

Después del golpe de Estado, tal como se ha señalado anteriormente, un grupo de trabajadores de la CMPC filial Laja fueron detenidos y ejecutados, sus cuerpos enterrados en forma clandestina en un fundo, siendo reconocida la inhumación de los cuerpos recién en 1979 a partir de una denuncia anónima. Ese mismo año, los restos fueron enterrados en el cementerio de Yumbel y se inició una investigación judicial que no tuvo grandes avances al declararse incompetente el juez. La causa fue traspasada a la justicia militar siendo sobreseída dos años después. En 2010, la causa fue reabierta bajo el juez Carlos Aldana, quien logró establecer los hechos y responsabilidades de los acusados.

El trabajo del juez Aldana fue confirmado con la resolución del 18 de marzo de 2018 de la Corte de Apelaciones de Concepción, mediante la cual se acogió un recurso presentado por los querellantes del Caso CMPC de Laja y se sometió a proceso como cómplices a tres jefes y un chofer de la Papelera, ${ }^{61}$ perteneciente a uno de los grupos empresariales más poderosos del país (familia Matte). La resolución reseña los hechos de la siguiente manera:

Que entre los días 13 y 14 de septiembre de 1973, en la puerta de accesosalida de la Planta Papelera CMPC de Laja fueron detenidos Fernando Grandón Gálvez, Jack Gutiérrez Rodríguez, Heraldo Muñoz Muñoz, Raúl Urra Parada, Federico Riquelme Concha, Juan Villarroel Espinoza y Wilson Muñoz Rodríguez por personal de Carabineros de la Tenencia de Laja, sin orden judicial ni administrativa competente. En dicho lugar, un sujeto mantenía una lista con cada una (sic) de los nombres de los detenidos, sindicando a Carabineros quienes eran cada uno de ellos, facilitando con ello su identificación y detención. ${ }^{62}$

De acuerdo con la resolución, entre el 13 y el 17 de septiembre fueron detenidos un grupo de trabajadores de la CMPC y trasladados en vehículos de la Papelera hasta la Tenencia de Laja. Los vehículos fueron facilitados por los jefes de la empresa y conducidos por un empleado de esta. Una comitiva de vehículos supuestamente trasladaría a los detenidos al Regimiento de la ciudad de Los Ángeles, pero la comitiva ingresó al Fundo San Juan y personal de carabineros hizo descender a los detenidos, obligándolos a tenderse en el suelo boca abajo, uno al lado del otro, amarrados de manos. El oficial al mando del traslado ordenó a los carabineros disparar a los detenidos, orden

61 Corte de Apelaciones de Concepción. Resolución Rol N. ${ }^{\circ}$ Sección criminal-Ant174-2017, 15 de marzo de 2018.

62 Corte de Apelaciones de Concepción. Resolución Rol N. ${ }^{\circ}$ Sección criminal-Ant174-2017, considerando primero a). 
que fue cumplida por todos, impactando con las balas los cuerpos de los detenidos, produciéndoles lesiones que les causaron la muerte. Acto seguido, los mismos funcionarios policiales, premunidos de palas que llevaron al efecto, cavaron una fosa de $60 \mathrm{~cm}$. de profundidad donde arrojaron los cuerpos, los que taparon con una capa de tierra, y días después volvieron al lugar cubriendo los cuerpos con cal de aquella que se utilizaba en la CMPC, la que fue proporcionada por funcionarios de la misma empresa. Finalizado este operativo, retornaron a la Tenencia de Laja, guardando silencio respecto de lo ocurrido. ${ }^{63}$

Los hechos fueron tipificados como homicidios calificados. En cuanto a la participación de los jefes y funcionarios de la empresa, la Corte los procesó como cómplices, señalando que Pedro Jarpa Forester, jefe de seguridad de la Papelera, "facilitó la detención de estos trabajadores de la misma empresa, proporcionando sus nombres, sindicándolos e identificándolos cuando ellos salían y entraban a la planta frente a Carabineros". Carlos Ferrer Gómez y Lionel Aguilera Covarrubias, "en su calidad de jefes de la papelera CMPC, proporcionaron a Carabineros de la Tenencia Laja los nombres de los trabajadores que a su juicio eran agitadores políticos colaborando con su detención en la puerta de acceso a la Planta, facilitaron vehículos y personal de choferes para su traslado y materiales como cal para cubrir sus cuerpos una vez que fueron asesinados". En el caso de Rodolfo Román Román, "actuó como chofer de los vehículos utilizados en el traslado de los detenidos, especialmente un jeep Land Rover, prestando colaboración en los ilícitos descritos". ${ }^{64}$

El Informe de la Comisión Nacional de Verdad y Reconciliación señala además que, en el año 1979, en el marco de investigaciones judiciales, se descubrió que en el mismo lugar en que fueron asesinadas las víctimas de Laja se encontraba el cuerpo de Luis Onofre Sáez Espinoza, empleado de la CMPC, militante del MAPU y dirigente del Sindicato N. ${ }^{\circ} 1$ de la empresa, quien se había presentado voluntariamente en la Comisaría de Los Ángeles, lugar en el que desapareció hasta que sus restos fueron encontrados. Dicha investigación posteriormente fue enviada a la justicia militar y sobreseída por aplicación de la Ley de Amnistía. ${ }^{65}$

\section{Caso Pesquera Arauco y Pesquera Chile}

63 Corte de Apelaciones de Concepción. Resolución Rol N. ${ }^{\circ}$ Sección criminal-Ant174-2017, considerando primero b).

64 Corte de Apelaciones de Concepción. Resolución Rol N. ${ }^{\circ}$ Sección criminal-Ant174-2017, considerando tercero.

65 Informe CNVR, 367. 
La Pesquera Arauco fue creada en la década de 1940 con apoyo de CORFO, como parte del proceso de fomento de industrialización del país. En 1967, CORFO poseía el $45,77 \%$ de la propiedad y la empresa se consolidó como "un grupo industrial que hasta 1973 lideró un nuevo ciclo de extracción de los recursos marinos". Después del golpe de Estado, asumió la presidencia del directorio de la empresa el coronel Manuel Contreras Sepúlveda, quien sería Director de la Dirección de Inteligencia Nacional, que se encontraba en proceso de formación. ${ }^{66}$

En febrero de 1975, la Compañía Pesquera Arauco fue vendida a la Empresa Pesquera Chile Ltda., también de CORFO. Manuel Contreras se mantuvo como presidente del Directorio, que fue integrado por oficiales de la DINA y empresarios. Tras diversos cambios societarios, aunque manteniéndose bajo el control de la DINA, la empresa fue liquidada en 1979 y sus derechos vendidos nuevamente a CORFO. ${ }^{67}$

El uso de vehículos de las pesqueras en el traslado de los detenidos se encuentra plenamente establecido en procesos judiciales. Sin embargo, existe solo un testimonio que asegura el uso de las dependencias de la empresa para el acopio de cadáveres, situación que se encuentra en investigación. ${ }^{68}$

Así se tiene el caso de María Angélica Andreoli Bravo, detenida en su domicilio por agentes de la DINA el 6 de agosto de 1974. Fue conducida al Cuartel Yucatán, ubicado en la calle Londres N. 38 de Santiago, donde fue vista por múltiples testigos, detenidos y detenidas que compartieron reclusión con ella en el mencionado recinto. María Angélica se encuentra desaparecida hasta la fecha.

En la investigación judicial por el secuestro y posterior desaparición de Andreoli Bravo prestaron declaración numerosos agentes de la DINA que ejercían funciones en el mencionado recinto. Uno de ellos, Fernando Guerra Guajardo, señaló en su testimonio que el retiro de los detenidos desde Londres 38 se hacía por orden del comandante del Cuartel, que se trasmitía verbalmente al jefe de guardia y agrega:

Al detenido se le llamaba por su nombre y se le llevaba en presencia del jefe del cuartel que se los entregaba a un agente, después los hacían subir a unas

66 Karinna Fernández y Magdalena Garcés Fuentes, "Los casos de la Pesquera Arauco y Colonia Dignidad”, en Bohoslavsky, Fernández y Smart, Complicidad económica, 391 y ss.

67 Ibid., 392-393.

68 La causa 201-2015 fue acumulada a la causa 202-2015, por asociación ilícita e inhumación ilegal de las 85 personas desaparecidas desde Londres 38, que sustancia el Ministro en Visita Mario Carroza y que se inició tras la interposición de una querella de Londres 38, espacio de memorias a fines del año 2015. Ver http://www.londres38.cl/1934/w3-article-98412.html 
camionetas o camiones cerrados. El camión tipo frigorífico chico de la pesquera se ponía al lado de la puerta y colocaban unos tableros para tapar la vista y estos egresos de detenidos se hacían normalmente en la noche tipo 24.00 horas, cuando no había gente en las calles. ${ }^{69}$

Desde el inicio de las investigaciones judiciales a mediados de los años setenta, ex detenidos y detenidas sobrevivientes de los recintos clandestinos de la Dirección de Inteligencia Nacional comenzaron a dar su testimonio por sus compañeras y compañeros desaparecidos. Muchas veces se relataba el traslado en camiones frigoríficos tipo 3/4 pertenecientes a la Pesquera Arauco.

Con el paso de los años, y con el desarrollo de los juicios por graves violaciones a los derechos humanos, las referencias a la pesquera se repetían. Sin embargo, la información se encontraba dispersa en diversos expedientes y la conocida "pesquera" no había sido investigada judicialmente de manera sistemática, a excepción de las diligencias realizadas en el proceso 2182-98 Operación Colombo-Aedo y otros. En diciembre de 2015, el ministro de la Corte de Apelaciones de Santiago Hernán Crisosto remitió los antecedentes reunidos en el proceso mencionado al ministro Mario Carroza, que inició un proceso sobre la pesquera. ${ }^{70}$

El sitio de memorias Londres 38 interpuso una querella criminal el año 2017 por los delitos de secuestro calificado, asociación ilícita e inhumación ilegal de las víctimas desaparecidas desde el cuartel de calle Londres 38, en contra de quienes formaron parte del Directorio y los representantes de la Empresa Pesquera Chile Ltda., sucesora de la Empresa Pesquera Arauco S.A. ${ }^{71}$

En la querella, se expone que 85 personas, hombres y mujeres, que pasaron en calidad de detenidos en el recinto clandestino de la DINA ubicado en Londres 38, se encuentran desaparecidos hasta la fecha. De acuerdo con la información reunida en los mismos procesos judiciales y sistematizada por Londres 38, vehículos de la empresa Pesquera Arauco S.A. fueron usados de manera habitual en el traslado de detenidos y detenidas hacia y desde el recinto de Londres 38, especialmente desde allí hasta Regimiento de Tejas Verdes en San Antonio, lugar desde el cual algunas víctimas no habrían retornado. La pesquera habría facilitado al organismo represivo tanto instalaciones como vehículos para el traslado de personas detenidas, algunas de las cuales se encuentran desaparecidas. ${ }^{72}$ Los traslados a San Antonio se

69 Ministro Hernán Crisosto Greisse, Sentencia Rol N. ${ }^{\circ} 2182-98$ Operación Colombo-María Angélica Andreoli. Sentencia de 10 de abril de 2015, considerando vigésimo séptimo letra $\mathrm{f}$.

70 Causa Rol 201-2015.

71 Sobre la interposición de la querella y el texto de la misma, ver https://www.londres38.cl/1937/w3-article-99099.html

72 Ídem. Ver también "Antecedentes para la investigación de patrones criminales usados en la desaparición de personas desde el recinto clandestino de detención 
realizaban al menos dos veces por semana entre los meses de enero a agosto o septiembre de 1974, periodo de funcionamiento de Londres 38 como centro secreto de detención y torturas. ${ }^{73}$

El uso de vehículos de la Pesquera para el traslado de detenidos continuó tras el cierre del cuartel de Londres 38. En una causa por la desaparición de 19 personas desde el Cuartel Terranova de la DINA, conocido como Villa Grimaldi, un testigo sobreviviente declara que vio cuando Juan René Molina Mogollones, a quien conocía y con quien compartió reclusión en el recinto, fue subido a un camión frigorífico de la Pesquera Arauco y llevado del lugar. Desde entonces se encuentra desaparecido. Según los testimonios de sobrevivientes en el mismo proceso, junto con Juan René Molina Mogollones, fue sacado un grupo de detenidos desde Villa Grimaldi, sin que se volviera a tener noticias de su paradero. ${ }^{74}$

\section{Colonia Dignidad}

En el año 1961, un grupo de alemanes liderados por el pastor Paul Schäfer Schneider se instaló en la zona centro sur de Chile. Bajo el amparo legal de una sociedad de beneficencia, fundación sin fines de lucro, comenzaron a comprar de manera legal o bajo coerción amplios territorios al interior de la zona de Parral, actual séptima región. ${ }^{75}$ El grupo de alemanes había acompañado a su líder, Paul Schäfer, quien debió huir de la justicia alemana acusado de abusos sexuales a niños. Muchos niños y niñas fueron traídos a Chile mediante engaños a sus padres, quienes no lograron recuperar a sus hijos.

Con apoyo de los estados chilenos y alemán, la secta formó un cerrado y poderoso enclave que permaneció libre de cualquier fiscalización de parte del Estado chileno, constituyéndose en lo que muchos calificaron de "un Estado al interior del Estado". ${ }^{76}$ En 1991, tras el fin de la dictadura, el presidente

ubicado en Londres 38", Documento elaborado por la abogada Karinna

Fernández, por encargo de Londres 38. Septiembre de 2016. Disponible en www.londres38.cl

73 Londres 38, espacio de memorias, Querella Criminal en contra de los miembros del directorio y representantes de Pesquera Chile S.A.

74. Ministro Alejandro Solís Muñoz, Sentencia Rol N. ${ }^{\circ}$ 182-98 Villa GrimaldiCuaderno principal, 27 de junio de 2014.

75 Por el Decreto Supremo N. ${ }^{\circ}$ 3949, del 21 de septiembre de 1961, se les concedió personalidad jurídica con el nombre de "Sociedad Benefactora y Educacional Dignidad”.

76 Para una visión general sobre la vinculación de Colonia Dignidad con las políticas represivas de la dictadura, ver Evelyn Hevia y Jan Stehle (eds.), Colonia Dignidad. Verdad, Justicia y Memoria (Santiago de Chile: Ediciones y publicaciones El Buen Aíre, 2015). 
Patricio Aylwin Azócar canceló la personalidad jurídica de la secta y dispuso el traspaso de sus bienes a la Iglesia Metodista. ${ }^{77}$ No obstante, los bienes de la Colonia ya habían sido traspasados a diversas sociedades comerciales dirigidas por los jerarcas del enclave alemán. ${ }^{78}$

Las denuncias de violaciones a los derechos humanos al interior de Colonia Dignidad, hoy "Villa Baviera", son de antigua data. De manera previa a la dictadura ya afectaron a los habitantes de la zona, despojándolos de sus bienes, y a los propios colonos, sometiéndolos a trabajos forzados, medicándolos con psicotrópicos para doblegar su voluntad, cometiendo abusos sexuales a los niños, etc., así como imposibilitándolos de abandonar el recinto o comunicarse con el exterior. ${ }^{79}$ Con los primeros intentos de fuga de colonos se empezaron a conocer denuncias de lo que sucedía al interior de Colonia Dignidad. Estas denuncias, sin embargo, no fueron investigadas: por el contrario, los fugados eran devueltos al enclave alemán con la venia de los dos Estados (chileno y alemán).

Con posterioridad al golpe de Estado, los jerarcas de la Colonia Dignidad comenzaron a colaborar con las autoridades del nuevo régimen participando activamente en graves violaciones a los derechos humanos en contra de detenidos políticos en la zona así como de otras personas detenidas que fueron llevadas expresamente el recinto para ser torturadas e interrogadas.

Investigaciones judiciales lograron establecer que Adán Valdebenito Olavarría y Pedro Juan Merino Molina, militantes de las Juventudes Comunistas (JJCC), detenidos en Lota y Coronel respectivamente, fueron trasladados a Colonia Dignidad, donde fueron torturados e interrogados; al igual que Álvaro Modesto Vallejos Villagrán, dirigente del MIR, detenido en Santiago en mayo de 1974. Los tres se encuentran desaparecidos. ${ }^{80}$ En procesos judiciales se logró establecer que decenas de personas detenidas por

77 Decreto N. ${ }^{\circ} 143$ de 1991 del Ministerio de Justicia.

78 Fernández y Garcés Fuentes, "Los casos de la Pesquera Arauco", 394 y ss.

79 Véase el caso del fugado Ernst Wolfgang Müller, condenado por el delito de injurias en contra de uno de los líderes de la colonia Hermann Schmidt. Müller denunció los crímenes que se cometían al interior de la colonia (Juzgado de Letras de Parral, Causa Rol N. ${ }^{\circ}$ 23.919, 23 de agosto de 1967. 50 años después, el 23 de agosto de 2017, la Corte Suprema acogió un recurso de revisión, invalidó la sentencia de 1967 y declaró absuelto a Ernst Wolfgang Müller Lilischkies, actualmente Ernst Wolfgang Kneese, "por haber sido probada satisfactoriamente su completa inocencia” (Corte Suprema, Sentencia Rol de 23 de agosto de 2017).

80 Ministro Jorge Zepeda Arancibia, Sentencia Rol No 27.707-2004 (Adscrita al Rol N. ${ }^{\circ}$ 2.182-98 Ex Colonia Dignidad), 29 de junio de 2011; Ministro Carlos Aldana Fuentes, Sentencia Rol N. ${ }^{\circ} 28.888,15$ de junio de 2010; Ministro Jorge Zepeda Arancibia, Sentencia Rol 2182-98 Episodio Álvaro Vallejos Villagrán, 7 de mayo de 2015. 
agentes estatales fueron trasladadas a este recinto, donde fueron torturadas y mantenidas prisioneras en precarias condiciones. Posteriormente pocas fueron liberadas y la mayoría entregadas a la Dirección de Inteligencia Nacional, DINA y trasladadas a recintos del organismo en Santiago. Estas personas recuperaron su libertad desde diversos campos de concentración. ${ }^{81}$

También se logró establecer que personal militar llevó detenidos al interior del fundo, donde fueron fusilados e inhumados en fosas previamente excavadas por los colonos. Posteriormente, en 1978, integrantes de la Colonia, bajo órdenes de Schäfer, desenterraron los restos y procedieron a quemarlos y lanzar las cenizas al rio Perquilauquén. ${ }^{82}$ Recientemente, en el marco de un proceso judicial, peritajes forenses lograron ubicar y delimitar la zona de la quema. ${ }^{83}$

En una de las principales investigaciones sobre crímenes cometidos al interior del recinto, Causa 2182-98 “Asociación Ilícita”, se logró establecer la existencia de una organización entre los ex jerarcas de la Colonia y altos mandos de la DINA para la comisión de variados delitos, entre ellos la detención de personas. Señala el fallo:

Efectivamente, aparece de los antecedentes reunidos por este tribunal que, con posterioridad al 11 de septiembre de 1973, la DINA, con conocimiento y en concierto con los jefes de la ex "Colonia Dignidad”, este enclave alemán implementó parte de sus actividades utilizando las instalaciones de la referida colonia alemana, secuestrando a civiles que fueron conducidos a ella y mantenidos en esa condición en su interior. ${ }^{84}$

El fallo constata la ubicación en Colonia Dignidad de vehículos pertenecientes a víctimas desaparecidas por la DINA, la elaboración de

archivos que contenían los datos y antecedentes de personas sindicadas como izquierdistas, muchas de las cuales se ignora hasta hoy su paradero; dando luz, por los interrogatorios cuyos registros han sido encontrados, respecto de los desaparecidos Álvaro Modesto Vallejos Villagrán y Pedro

81 Ministro Jorge Zepeda Arancibia, Sentencia Rol N. ${ }^{\circ}$ 10- 2004 (Adriana Bórquez Adriazola), 15 de abril de 2013; Ministro Jorge Zepeda Arancibia, Sentencia Rol $\mathrm{N}^{\circ}$ 49-2004, adscrita al Rol N. ${ }^{\circ} 2.182-98,15$ de octubre de 2015. Ver también procesos Rol N. ${ }^{\circ} 2182-98$-Erick Zott Chuecas y Luis Enrique Peebles Skarnic, con sobreseimiento temporal y Rol N. ${ }^{\circ}$ 5-2018, sustanciada por la Ministra en Visita Yolanda Méndez Mardones, en etapa de sumario.

82 Ministro Jorge Zepeda Arancibia, sentencia Rol N. ${ }^{\circ} 2182-98$ Asociación ilícitaex Colonia Dignidad, 9 de abril de 2014; y Causa Rol N. ${ }^{\circ}$ 182-98 episodio Juan Bosco Maino Canales y otros, sustanciada por el Ministro de Fuero Jorge Zepeda Arancibia. Sentencia de 23 de enero de 2012.

83 Causa Rol N. ${ }^{\circ}$ 683-2017, sustanciada por el Ministro en Visita Mario Carroza Espinosa, en etapa de sumario.

84 Ministro Jorge Zepeda Arancibia, sentencia Rol N. ${ }^{\circ}$ 2182-98 Asociación ilícita, considerando tercero letra c). 
Merino Molina de que los últimos días en que se tuvo noticia de ellos, se encontraban secuestradas en la ex "Colonia Dignidad". 85

En la sentencia se caracteriza la organización interna como "una estructura jerarquizada que planificó y ejecutó múltiples delitos, integrada por personas que fueron miembros y colaboradores de esa corporación, actividad que se inicia a lo menos desde el año 1970". ${ }^{86}$ El fallo detalla la comisión de otros graves delitos, como la tenencia de armamento que incluía armas de guerra, armas de "fantasía", ${ }^{87}$ explosivos y armas químicas, así como tráfico de armas; lesiones graves a los colonos a través de tratamientos psiquiátricos y abusos sexuales en contra de niños.

A pesar de los graves delitos enumerados, Paul Schäfer murió en prisión preventiva, sin haber recibido condena. En innumerables procesos, los principales jerarcas fueron condenados a penas ínfimas, ingresando a prisión por complicidad en abusos sexuales, causa investigada por un ministro de la Corte de Apelaciones de Talca que no veía procesos de derechos humanos y dictó la primera condena a pena efectiva. ${ }^{88}$ Posteriormente, los jerarcas sobrevivientes fueron condenados a cinco años y un día por el delito de asociación ilícita, pena impuesta por la E. Corte Suprema, que por medio de un recurso de casación elevó la pena originalmente menor, impidiendo la concesión de beneficios carcelarios. ${ }^{89}$

Además de la ejecución de innumerables delitos, Colonia Dignidad aprovechó la pasividad y complicidad de los Estados chileno y alemán. Hasta la disolución de su personalidad jurídica en 1991, sus negocios estuvieron exentos de impuestos y gozaron de beneficios aduaneros por tratarse de una "sociedad benefactora" sin fines de lucro. Los jerarcas cobraron las pensiones alemanas de los colonos y colonas esclavizados en su interior sin ninguna fiscalización de las autoridades alemanas. El trabajo no era remunerado ni se pagaron cotizaciones previsionales de ningún tipo: los niños debían realizar pesados trabajos en el campo por cuanto no existía fiscalización alguna de su escolarización. Hasta la fecha, pese a existir una sentencia ejecutoriada en su

85 Ibid.

86 Ministro Jorge Zepeda Arancibia, sentencia Rol N. ${ }^{\circ}$ 2182-98 Asociación ilícita, considerando tercero, letra a).

87 Sostiene el fallo: "Otros elementos incautados estarían destinados a efectuar ataques especialmente odiosos, como es el caso de las armas de fantasía, encubiertas bajo la forma de lápices, bastones de apoyo para caminar y cámara fotográfica con dardos en su obturador, fabricados especialmente para ocultar su verdadera naturaleza”. Ministro Jorge Zepeda Arancibia, sentencia Rol N. ${ }^{\circ}$ 2182-98 Asociación ilícita, considerando tercero letra b).

88 Ministro Hernán González García, Sentencia en Causa Rol N. ${ }^{\circ}$ 53.015-96 del Juzgado de Letras de Parral (y acumuladas Rol N. ${ }^{\circ} 53.914,54.712$ y 54.713), 16 de noviembre de 2004.

89 CS, Sentencia Rol N. ${ }^{\circ}$ 14.312-16, 29 de diciembre de 2016. 
contra, los actuales directivos de "Villa Baviera" no cancelan las indemnizaciones establecidas judicialmente a favor de los niños abusados. No existe constancia del destino de gran parte de los fondos que la Colonia acumuló en la dictadura.

Por otra parte, al igual que en otros casos, la investigación judicial fue parcial y limitada, con muchos vacíos, falta de sistematicidad y urgencia, no estableciéndose hasta la fecha la identidad de las muchas personas desaparecidas al interior del recinto o la responsabilidad de colonos en la comisión de los delitos. Muchos jerarcas fallecieron sin enfrentar la justicia. Al mismo tiempo, varios colonos lograron fugarse a Alemania, siendo emblemático el caso del doctor Harmut Hopp, quien colaboró activamente con la DINA. Hopp se refugió en Alemania donde logró evitar el cumplimiento de la sentencia en su contra por no contemplar el Estado alemán la extradición de sus nacionales.

Los casos identificados anteriormente dan cuenta de la acción concertada de civiles y agentes del Estado para reprimir y castigar a hombres y mujeres que participaron activamente en el proceso político de la Unidad Popular en procura de un cambio en sus condiciones de vida. La brutalidad de los hechos consignados viene a reafirmar el carácter sistemático de la represión y el objetivo de restaurar el orden social perdido según los defensores del golpe de Estado y su proyecto refundacional.

\section{Conclusiones}

A través de la lectura de las páginas precedentes podemos realizar algunas reflexiones que ayuden a alimentar el debate sobre la responsabilidad empresarial en los crímenes de la dictadura. En Chile, el tema ha tenido un desarrollo reciente, a diferencia de otras experiencias internacionales, como el caso argentino, donde una serie de investigaciones y trabajos conforman un amplio corpus que ha permitido desentrañar la relevancia del rol de los civiles en la guerra sucia y en general el combate contra el movimiento sindical por parte de los aparatos de seguridad. Estos estudios han sido fundamentales para sostener la base argumentativa en las causas seguidas en tribunales en contra de personeros empresariales por su responsabilidad en crímenes de lesa humanidad.

En Chile, en cambio, las investigaciones sobre el rol de los civiles en casos de crímenes de derechos humanos han tenido fundamentalmente un tratamiento de corte periodístico, tomando como fuentes los expedientes judiciales donde se concentra la información emanada de los juicios. En este sentido, el rol de las organizaciones de derechos humanos, familiares de víctimas, sobrevivientes y abogados ha sido fundamental para la búsqueda de la verdad 
en los casos que involucraron a civiles, especialmente empresarios y empresas o en áreas donde se dio fuertemente la confrontación social durante la Unidad Popular como fueron las experiencias de reforma agraria.

Por lo tanto, como campo de interés historiográfico, el rol de las empresas o los empresarios como partícipes de la represión tiene un potencial investigativo y de reflexión porque permitiría cuestionar ciertos supuestos que se han construido sobre el papel de los civiles en la pasada dictadura y su ligazón con la parte "benigna" del proceso dictatorial, lo que se ha denominado el legado de la dictadura. En ese sentido, el referirnos al modelo neoliberal con un rostro sangriento, no responde simplemente a una metáfora, sino a una especie de "pecado de origen" de la dictadura, que marcará su trayectoria y definirá las relaciones sociales en el mismo periodo.

De este modo, podemos establecer ciertas tendencias con relación a la acción de los empresarios; por una parte, podemos identificar su participación individual, especialmente en el mundo rural, en casos vinculados al proceso de reforma agraria donde después del golpe de Estado los antiguos propietarios protagonizaron la contrarreforma con sus efectos represivos y disciplinadores. Sin embargo, estos civiles como Luis García, Juan Francisco Luzoro o Enrique Sandoval Poo, formaban parte de colectivos de personas (transportistas, latifundistas, comerciantes) que apoyaron y/o participaron también del proceso represivo. Sandoval Poo era uno de los "pilotos civiles" que contribuyeron a la represión en la ciudad de Temuco; Juan Luzoro no fue el único civil y/o empresario de transportes que participó en la represión de la localidad de Paine, ni lo hizo a título individual.

También se encuentran casos donde la responsabilidad recae en empresas, ${ }^{90}$ correspondiendo a los casos de la CMPC en Laja, Colonia Dignidad y Pesquera Arauco, donde operó toda una logística e infraestructura al servicio de los objetivos represivos generándose una colaboración civil-militar que vendría a cuestionar el papel "positivo" de los civiles en el desarrollo de la dictadura del general Pinochet.

De acuerdo a estas consideraciones, podemos señalar que en general existiría un cuadro de impunidad o ausencia de castigo en relación a la participación de los empresarios y las empresas en crímenes contra los derechos humanos. Tampoco se pueden desconocer, sin embargo, los pequeños pero importantes avances conseguidos en los últimos años, gracias a la labor de los organismos de derechos humanos, de familiares de las víctimas, de los y las sobrevivientes y sus abogados y abogadas, de tal manera que junto a este marco general de

90 A la fecha de ocurrencia de los hechos, la responsabilidad criminal sólo podía recaer en personas naturales, lo que implica que las empresas no pueden ser juzgadas penalmente por crímenes cometidos en aquella época, sino sólo los individuos. 
impunidad se encuentran trazos de una justicia parcial. Son logros que se explicarían también en la medida que los pesados legados de la dictadura y la transición van quedando atrás: las sombras de un pasado oscuro vienen a interpelar a las generaciones más jóvenes, interrogándose sobre los déficits de falta de justicia, pero también planteándose nuevas inquietudes que ayuden a construir una lectura más completa de la dictadura cívico-militar 
Title: “The Model Has Blood on Its Face”. Corporate Responsibility in Repressive Processes during the Pinochet Dictatorship in Chile. (1973-1990)

Abstract: This article analyzes the responsibility of business sectors in the repressive policy of the civil-military dictatorship in Chile. It draws upon secondary literature, to understand the repressive context, and lawsuits on human rights violations in which people linked to the business sector participated. Based on this research, it argues that civilians had active participation in the commission of crimes. This puts into question the beneficial image that business groups managed to build about themselves in relation to their role in the dictatorship and engages with current debates about the inheritance of that regime.

Keywords: human rights, business, repression, trials, civil-military dictatorship

Titulo: "O modelo tem a face do sangue". Responsabilidade corporativa em processos repressivos durante a ditadura de Pinochet no Chile (1973-1990)

Resumo: Este artigo tem como objetivo analisar a responsabilidade dos setores empresariais na política repressiva da ditadura civil-militar chilena. Para isso, utiliza a bibliografia para compreender o contexto repressivo e analisa casos legais de violação dos direitos humanos nos quais pessoas ligadas ao setor empresarial estavam envolvidas. De acordo com a pesquisa, argumentamos que os civis estavam ativamente envolvidos na comissão de crimes. Isto vem a questionar a imagem benéfica que os grupos empresariais conseguiram construir sobre si mesmos em relação ao seu papel na ditadura, um questionamento que se insere nos debates sobre a herança ditatorial.

Palavras-chave: direitos humanos, negócios, repressão, julgamentos, ditadura civil-militar 